\title{
Desempenho agronômico de mandioca de mesa manejada com irrigação e uso de cobertura plástica do solo
}

\author{
Jorge Cesar dos Anjos Antonini ${ }^{1}$, Eduardo Alano Vieira ${ }^{1}$, Josefino de Freitas Fialho ${ }^{1}$, Fernando Antônio \\ Macena ${ }^{1}$, Krishna Naudinn ${ }^{2}$, Juaci Vitória Malaquias ${ }^{1}$ \\ ${ }^{1}$ Embrapa Cerrados, Brasília - DF. ${ }^{2}$ Centre de Coopération Internationale en Recherche Agronomique pour le \\ Développement (CIRAD). E-mail: eduardo.alano@embrapa.br
}

\section{Resumo}

Apesar da mandioca ser reconhecida pela sua elevada tolerância à seca, a irrigação vem apresentando resultados satisfatórios. Entretanto, poucos estudos vêm sendo desenvolvidos visando a determinação dos efeitos da cobertura do solo, da irrigação e da combinação de ambos no desenvolvimento da cultura. 0 objetivo deste estudo foi determinar a influência da irrigação e da cobertura plástica do solo, no desempenho agronômico de mandioca de mesa. O plantio foi feito em canteiros, no sistema de fileira dupla com as manivas-sementes implantadas na vertical em espaçamento de $0,60 \mathrm{~m}$ entre linhas e 0,80 $\mathrm{m}$ entre plantas. Foram aplicados os tratamentos canteiro desnudo sem irrigação, canteiro coberto com plástico de polietileno preto sem irrigação, canteiro desnudo com irrigação e canteiro coberto com plástico de polietileno preto com irrigação. As irrigações foram por aspersão convencional, com base no balanço diário de água do solo na profundidade efetiva do sistema radicular da mandioca nos diferentes estágios de desenvolvimento da cultura. Os caracteres avaliados em duas safras foram: produtividade de parte aérea, produtividade de raízes, porcentagem de amido nas raízes e tempo para a cocção. A expressão dos caracteres produtividade de raízes, peso da parte aérea e teor de amido nas raízes, foi influenciada pelo manejo da irrigação e pela cobertura do solo. A utilização individual das tecnologias de irrigação e de cobertura plástica do solo, proporcionaram aumentos de produtividade de raízes de $55 \%$ e $13 \%$, respectivamente, e quando foram utilizadas em conjunto a produtividade de raízes aumentou $89 \%$.

Palavras-chaves: Manihot esculenta Crantz; manejo de água; plasticultura; produtividade de raízes; sistema de produção.

\section{Agronomic performance of sweet cassava managed with irrigation and use of plastic soil cover}

\begin{abstract}
Although cassava is recognized for its high tolerance to drought, irrigation is showing satisfactory results. However, few studies have been carried out to determine the effects of soil cover, irrigation and the combination of both on crop development. The objective of this study was to determine the influence of irrigation and plastic soil cover on the agronomic performance of sweet cassava. The planting was done in beds, in the double row system with the stem cutings implanted vertically, with $0.60 \mathrm{~m}$ between rows and $0.80 \mathrm{~m}$ between plants. The following treatments were applied: naked non-irrigated bedding, bedding covered with non-irrigated black polyethylene plastic, naked bedding with irrigation and bedding covered with irrigated black polyethylene plastic. Irrigation was performed by conventional sprinkling, based on the daily soil water balance at the effective depth of the cassava root system in the different stages of crop development. The characters evaluated were: shoot weight, root yield, starch percentage in the roots and time for cooking. The expression of the characters shoot weight, root yield and starch percentage in the roots was significantly influenced by irrigation management and soil cover. The individual use of irrigation and plastic soil cover technologies led to increases in root yield of $55 \%$ and $13 \%$, respectively, and when used together, root yield increased by $89 \%$.
\end{abstract}

Additional keywords: Manihot esculenta Crantz; mulching; root yield; system of production; water management. 


\section{Introdução}

A mandioca de mesa (Manihot esculenta Crantz) é um dos principais cultivos das áreas rurais, das regiões metropolitanas brasileiras (MENDONÇA et al., 2020). A espécie é cultivada visando o consumo culinário (cozida, frita, chips, mandioca palito, pré-cozida, entre outras) de suas raízes de reserva. $O$ cultivo é dos preferidos dos horticultores em razão da lucratividade e adaptação à rotação e/ou sucessão de cultivo com outras hortaliças (MENDONÇA et al., 2020).

$O$ grande desafio do sistema de produção de mandioca de mesa é aliar produtividade, precocidade, qualidade das raízes de reserva e diminuição do uso de mão-de-obra na lavoura (FIALHO et al., 2017). Dessa forma, o setor produtivo vem demandando tecnologias que maximizem a lucratividade e a qualidade dos produtos oferecidos aos consumidores.

Essa demanda pode ser atendida tanto por meio da geração de cultivares, como pelo desenvolvimento de novas técnicas de manejo. Nesse sentido, a pesquisa vem obtendo resultados expressivos quanto à geração de cultivares de mandioca de mesa com produtividade e qualidade culinária (VIEIRA et al., 2011; 2018).

A diminuição da mão-de-obra para a condução da lavoura poderia ser otimizada por meio da utilização de cobertura do solo, tecnologia que auxilia no controle de plantas daninhas, manutenção da umidade, diminuição da erosão e melhoria da qualidade biológica do solo (GHUMAN; LAL, 1983; LIMA et al., 2015).

Apesar da mandioca ser reconhecida pela sua elevada tolerância à seca, a irrigação é outra tecnologia que vem apresentando resultados satisfatórios para o cultivo de mandioca (GHUMAN; LAL, 1983; SOUZA et al., 2010; PASTRANA et al., 2015; ADJEBENG-DANQUAH et al., 2016). Entretanto, poucos estudos vêm sendo desenvolvidos visando a determinação dos efeitos da cobertura do solo, da irrigação e da combinação de ambos no desenvolvimento da cultura.

Neste trabalho, objetivou-se determinar a influência da irrigação e da cobertura plástica do solo no desempenho agronômico da cultivar de mandioca de mesa BRS 399.

\section{Material e Métodos}

Os experimentos foram conduzidos por duas safras no campo experimental da Embrapa Cerrados, localizado em Planaltina-DF $\left(15^{\circ} 35^{\prime} 28^{\prime \prime}\right.$ $\mathrm{S}$ e $47^{\circ} 42^{\prime} 37^{\prime \prime} \mathrm{W}$ a $1.007 \mathrm{~m}$ de altitude), entre novembro de 2015 e setembro de 2016 e, entre dezembro de 2016 e outubro de 2017. O clima do local, de acordo com a classificação de Koppen, é do tipo megatérmico ou tropical úmido (A), com o subtipo clima de savana, com inverno seco e chuvas máximas de verão (w) e, com temperatura média do mês mais frio acima de $18^{\circ} \mathrm{C}$. O solo é denominado Latossolo Vermelho distrófico de textura argilosa (EMBRAPA, 2018).

As variáveis climáticas foram coletadas por meio de estação meteorológica, localizada a $300 \mathrm{~m}$ do local de condução dos experimentos. As variáveis consideradas para análise foram temperatura, umidade relativa do ar, velocidade do vento, horas de insolação, radiação solar global e precipitação. A evapotranspiração de referência foi estimada a partir do método micrometeorológico de Penman-Monteith, adaptado por Allen et al. (1998).

As composições químicas e físicas do solo nas safras 2015/2016 e 2016/2017 foram de $\mathrm{pH}$ em $\mathrm{H}_{2} \mathrm{O} 6,0$ e $5,5, \mathrm{Ca}^{+2} 3,0$ e $3,1 \mathrm{cmol}_{\mathrm{c}} \mathrm{dm}^{-3}, \mathrm{Mg}^{+2}$ 1,3 e $1,5 \mathrm{cmol}_{\mathrm{c}} \mathrm{dm}^{-3}$, P 12,9 e $9,3 \mathrm{mg} \mathrm{dm}^{-3}, \mathrm{~K} 71,8$ e $102 \mathrm{mg} \mathrm{dm}^{-3}$, matéria orgânica 2,5 e 2,4\%, argila 52,26 e $51,22 \%$, areia 40,35 e $41,52 \%$ e silte 7,39 e $7,26 \%$, respectivamente. A capacidade de campo foi determinada pelo método direto (EMBRAPA, 1979), em tabuleiro de 1,00 m x 1,00 $\mathrm{m}$ localizado ao lado das parcelas experimentais.

Utilizou-se a cultivar de mandioca de mesa BRS 399, em razão dessa cultivar apresentar elevado desempenho agronômico na região do Distrito Federal (VIEIRA et al., 2018). O delineamento experimental utilizado foi de blocos casualizados, em arranjo fatorial $2 \times 4$ (safra $x$ tratamento), com quatro repetições.

O fator safra foi composto pelos níveis safras 2015/2016 e 2016/2017 e os tratamentos pelos níveis: i) canteiro desnudo sem irrigação complementar; ii) canteiro coberto com plástico opaco de polietileno preto de $50 \mu \mathrm{m}$ de espessura sem irrigação complementar, iii) canteiro desnudo e com irrigação complementar; e iv) canteiro coberto com plástico opaco de polietileno preto de $50 \mu \mathrm{m}$ de espessura e com irrigação complementar.

O experimento foi implantado sobre canteiros com 1,10 m de largura de terraço, com espaçamento de 1,40 m entre os canteiros. Cada 
parcela experimental foi composta por $80 \mathrm{~m}^{2}$, contendo quatro fileiras duplas divergentes, com espaçamento de $0,60 \mathrm{~m}$ entre fileiras simples, $1,90 \mathrm{~m}$ entre fileiras duplas e $0,80 \mathrm{~m}$ entre plantas (Figura 1). A área útil foi representada pelos $20 \mathrm{~m}^{2}$ centrais de cada parcela. As manivas- sementes foram plantadas na posição vertical, sendo que a seleção do material de propagação e a adubação seguiram as recomendações para a região do Cerrado (FIALHO et al., 2013; FIALHO; VIEIRA, 2013).

Figura 1. Croqui representativo da parcela do experimento conduzido para determinar a influência da irrigação e da cobertura plástica do solo no desempenho agronômico da cultivar de mandioca de mesa BRS 399.

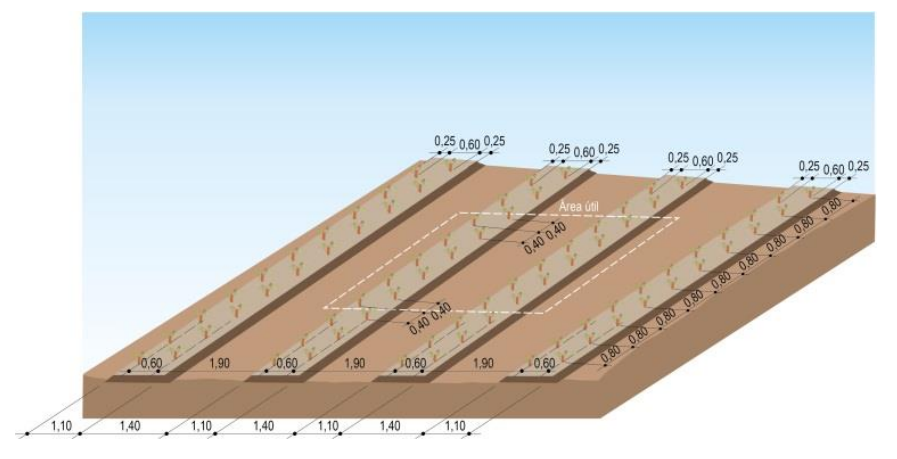

Imediatamente antes da colocação da cobertura plástica e do plantio, foi realizada uma amostragem de solo, na profundidade de $0,40 \mathrm{~m}$, para determinação da umidade do perfil, com vistas a realizar uma irrigação para elevar a umidade do solo à capacidade de campo e iniciar o balanço de água do solo. Logo após o plantio, foram abertos orifícios de $3 \mathrm{~cm}$ de diâmetro, entre as plantas nas parcelas dos tratamentos canteiro coberto com plástico opaco de polietileno preto de $50 \mu \mathrm{m}$ de espessura com e sem irrigação complementar, de forma a facilitar a penetração da água no solo. Os orifícios foram abertos nas linhas de plantio, com espaçamento de $0,80 \mathrm{~m}$.

O manejo da irrigação foi feito com base no balanço diário de água do solo na profundidade efetiva do sistema radicular da mandioca $(0,40 \mathrm{~m})$. Após o plantio foi aplicada irrigação com lâmina de água necessária para elevar a umidade do solo, novamente, à capacidade de campo. Em sequência, foi realizado o controle diário da evapotranspiração da cultura (ETc), precipitação efetiva $(\mathrm{Pe})$ e lâmina de irrigação aplicada (La). Adotou-se para cada estágio de desenvolvimento o respectivo coeficiente de cultura (Kc) e fator de disponibilidade de água (f). Utilizou-se no primeiro estágio ( 0 a 60 dias após o plantio) $\mathrm{Kc}=$ 0,5 e $f=0,2$, no segundo estágio (61 a 150 dias após o plantio) $\mathrm{Kc}=1,0$ e $\mathrm{f}=0,6$ e no terceiro estágio (151 a 300 dias após o plantio) $\mathrm{Kc}=0,8 \mathrm{e}$ $\mathrm{f}=0,6$ (ANTONINI et al., 2017).

A evapotranspiração da cultura foi estimada pelo produto entre a evapotranspiração de referência (ETo), o coeficiente de cultura (Kc) e o fator de disponibilidade de água no solo (f), do respectivo estágio de desenvolvimento da cultura. A ETo foi estimada pela equação de Penman-Monteith, alimentada com dados obtidos da estação meteorológica próxima da área experimental. A precipitação efetiva considerada foi à chuva que infiltrou no solo e permaneceu disponível para planta entre o ponto de murcha permanente e a capacidade de campo.

As irrigações foram realizadas por aspersão convencional, quando o balanço de água do solo, acusava o esgotamento da água total disponível, relativo ao (f) do estágio considerado e a lâmina aplicada foi majorada para considerar eficiência de aplicação de água de $85 \%$.

No momento da colheita foram avaliados quatro caracteres agronômicos: i) produtividade de parte aérea sem a cepa em $\mathrm{kg} \mathrm{ha}^{-1}$ (PPA); ii) produtividade de raízes em $\mathrm{kg} \mathrm{ha}^{-1}(\mathrm{PR})$; iii) porcentagem de amido nas raízes por meio do método da balança hidrostática (AM), descrito por Grosmann e Freitas (1950); e iv) tempo para a coç̧ão em minutos (TC) de acordo com Borges et al. (2002).

Os dados foram submetidos à análise de variância segundo o delineamento blocos ao 
acaso em esquema fatorial $2 \times 4$ (safras $x$ tratamentos). Para análise da hipótese de normalidade dos dados foi utilizado o teste Shapiro-Wilk's a 5\% de probabilidade de erro. As médias dos caracteres foram agrupadas por meio do teste aglomerativo de Scott e Knott (1974). As análises estatísticas foram realizadas por meio do Software R, versão 3.4.3 (R CORE TEAM, 2017) e Genes (CRUZ, 2016).

\section{Resultados e Discussão}

Nos períodos de condução dos experimentos, safras 2015/2016 e 2016/2017, as médias das temperaturas máximas diárias foram de 29,72 e $28,74^{\circ} \mathrm{C}$, das temperaturas mínimas diárias foram de 16,26 e $15,70^{\circ} \mathrm{C}$, das temperaturas médias diárias foram de 22,33 e $21,58^{\circ} \mathrm{C}$, de umidade relativa do ar foram de 63,23 e $62,96 \%$, as velocidades médias do vento foram de 1,77 e 1,87 $\mathrm{m} \mathrm{seg}^{-1}$, as médias de horas de insolação diária foram de 7,72 e 7,86 h, as médias de radiação diária foram de 19,16 e 18,95 $\mathrm{MJ} \mathrm{m} \mathrm{m}^{-1} \mathrm{dia}^{-1}$, as precipitações acumuladas foram de 705 e $500 \mathrm{~mm}$ e as médias de evapotranspiração potencial foram de 4,21 e 4,18 $\mathrm{mm}$, respectivamente (Figura 2 ).

Figura 2. Valores diários da precipitação em $\mathrm{mm}(\mathrm{P})$, das temperaturas máximas em ${ }^{\circ} \mathrm{C}(\mathrm{Tmáx}$.), das temperatura mínimas em ${ }^{\circ} \mathrm{C}$ (Tmín.) e da evapotranspiração de referência em $\mathrm{mm}$ (Eto), observados na estação climatológica principal da Embrapa Cerrados nas safras 2015/2016 (S1) e 2016/2017 (S2).

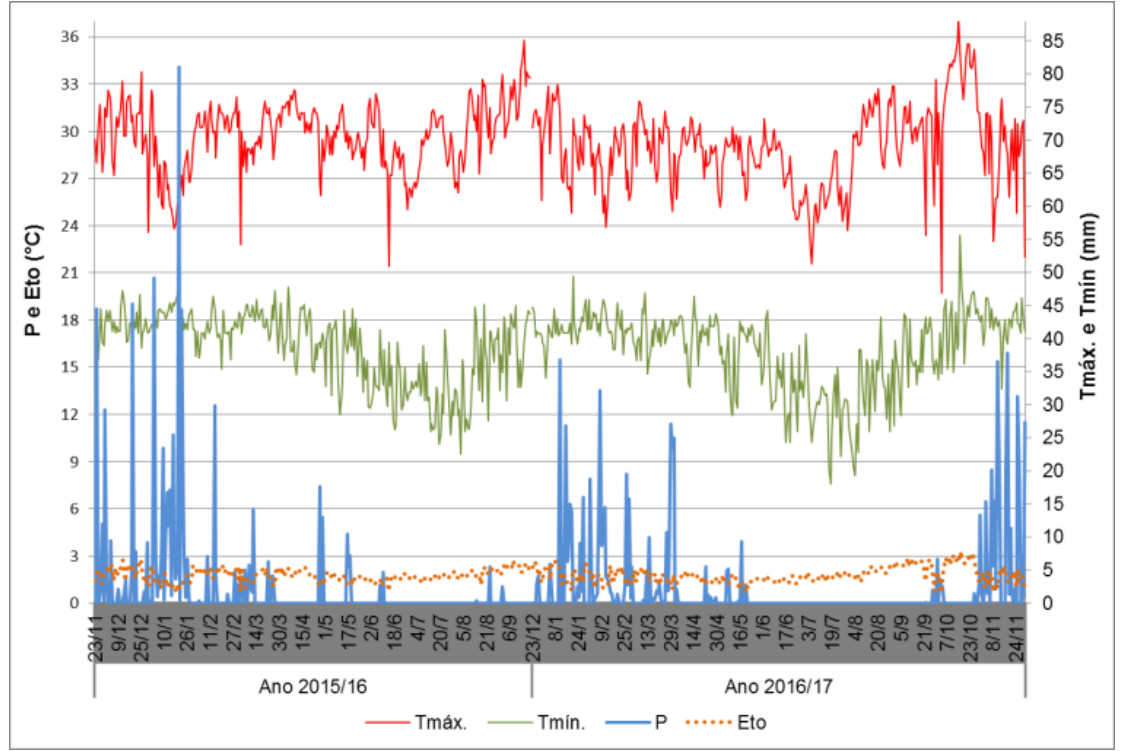

Tais resultados revelam que nos períodos de condução dos experimentos as temperaturas situaram-se dentro da faixa ótima de desenvolvimento da cultura da mandioca, que segundo El-Sharkawy (2004) é de $16^{\circ} \mathrm{C}$ a $37^{\circ} \mathrm{C}$. A precipitação total registrada na safra 2015/2016 foi superior à registrada na safra 2016/2017 e para as demais variáveis analisadas não houve variações expressivas entre os anos (Figura 2).

O consumo total de água das plantas foi de $902 \mathrm{~mm}$ na safra 2015/2016 e $856 \mathrm{~mm}$ na safra 2016/2017 (Tabela 1). A proximidade entre os valores pode ser explicada tanto pelo fato das evapotranspirações potenciais terem sido muito próximas nas duas safras (Figura 2), como pelos experimentos terem sido conduzidos no mesmo local e com a utilização da mesma cultivar.
O consumo médio de água de irrigação foi de $665 \mathrm{~mm}$, em um ciclo de dez meses, e o intervalo médio entre irrigações, na época seca (de abril a setembro) foi de 8,31 dias com lâmina média líquida aplicada por irrigação de $27 \mathrm{~mm}$ (Tabela 1). Em experimento conduzido na Colômbia, Pastrana et al. (2015) relataram a aplicação de lâmina de água de $22 \mathrm{~mm}$ a cada oito dias na época da seca, totalizando aplicação de água por irrigação de $406 \mathrm{~mm}$ em ciclo de nove meses de cultivo. Adjebeng-Danquah et al. (2016), relataram consumo de água de $853 \mathrm{~mm}$ em ciclo de 12 meses, em área de savana em Gana na África, com irrigação na época seca de $11 \mathrm{~mm}$, duas vezes por semana. Já Ghuman e Lal (1983), em experimento conduzido na Nigéria, relataram a aplicação de $665 \mathrm{~mm}$ de água, com 
irrigação na época da seca de $16 \mathrm{~mm}$, duas vezes por semana.

Tabela 1. Lâmina de água de irrigação, lâmina de água da chuva, lâmina de água consumida e média de irrigação em milímetros na estação seca e o intervalo entre irrigações na estação seca, nas safras 2015/2016 (S1) e 2016/2017 (S2) da cultivar de mandioca de mesa BRS 399 em ciclo de 10 meses, nas condições edafoclimáticas do Distrito Federal.

\begin{tabular}{|c|c|c|c|}
\hline \multirow{2}{*}{ Parâmetros estimados } & \multicolumn{2}{|c|}{ Safra } & \multirow{2}{*}{ Média } \\
\hline & S1 & S2 & \\
\hline Lâmina de água de irrigação (mm) & 667 & 662 & 665 \\
\hline Lâmina de água da chuva (mm) & 236 & 194 & 215 \\
\hline Lâmina total de água (mm) & 902 & 856 & 879 \\
\hline Lâmina média de irrigação na estação seca (mm) & 27 & 27 & 27 \\
\hline Intervalo entre irrigações na estação seca (dias) & 8,5 & 8,1 & 8,3 \\
\hline
\end{tabular}

As variações nos intervalos de irrigação e nas lâminas de água aplicadas são consequência direta dos critérios de determinação do momento da irrigação, se fixados anteriormente à implantação do ensaio (GHUMAN; LAL, 1983; ADJEBENG-DANQUAH et al.; 2016) ou se determinados de acordo com o ciclo da cultura e as condições ambientais, como no presente trabalho e no de Pastrana et al. (2015).

A análise de variância revelou a existência de diferenças significativas entre as médias das safras 2015/2016 e 2016/2017 apenas para produtividade de raízes (PR) (Tabela 2), indicando que apenas a média desse caráter foi influenciada pelo fator safra. A influência do fator safra sobre a produtividade de raízes é comum nas condições do Cerrado do Brasil Central (SILVA et al., 2014; VIEIRA et al., 2015a; FUHRMANN et al., 2019; PAZ et al., 2020), revelando a forte influência de fatores ambientais sobre a manifestação desse caráter. $O$ teste de Shapiro-Wilk's revelou que os resíduos dos caracteres avaliados apresentam distribuição normal a $5 \%$ de probabilidade de erro (Tabela 2).

Contudo, o fator safra não influenciou significativamente a média dos caracteres produtividade de parte aérea (PPA), teor de amido nas raízes (AM) e tempo para a cocção das raízes (TC) (Tabela 2). Uma provável explicação para a inexistência de variação no presente estudo, pode ter por base a estabilidade fenotípica do cultivar BRS 399 para os referidos caracteres (VIEIRA et al., 2018), uma vez que trabalhos conduzidos na região do Cerrado vêm demonstrando influência do fator safra na manifestação desses caracteres quando são avaliados vários genótipos concomitantemente (SILVA et al., 2014, VIEIRA et al., 2015a,b; FUHRMANN et al., 2019; PAZ et al., 2020).

Tabela 2. Resumo da análise de variância e coeficiente de variação dos caracteres produtividade de parte aérea sem a cepa em $\mathrm{kg} \mathrm{ha}^{-1}$ (PPA), produtividade de raízes em $\mathrm{kg} \mathrm{ha}^{-1}(\mathrm{PR})$, porcentagem de amido nas raízes (AM) e tempo para a cocção em minutos (TC) avaliados na cultivar de mandioca BRS 399 nas safras 2015/2016 e 2016/2017 submetida aos tratamentos canteiro desnudo sem irrigação (CSPSI), canteiro coberto com plástico sem irrigação complementar (CCPSI), canteiro desnudo e com irrigação complementar (CSPCI) e canteiro coberto com plástico e com irrigação complementar (CCPCI).

\begin{tabular}{lccccc}
\hline \multirow{2}{*}{ FV } & \multirow{2}{*}{$\mathrm{GL}$} & \multicolumn{5}{c}{$\mathrm{QM}$} \\
\cline { 3 - 6 } & & PPA & PR & AM & TC \\
\hline Blocos (B) & 3 & 1119666 & 5897246 & 3,50 & 2,86 \\
Safras (S) & 1 & 950476 & $511728036^{*}$ & 2,15 & 2,70 \\
Tratamentos (T) & 3 & $450915080^{*}$ & $470344014^{*}$ & $4,39^{*}$ & 0,03 \\
Tx S & 3 & 4236853 & 4630733 & 1,01 & 0,45 \\
Resíduo (R) & 21 & 1652648 & 2971833 & 0,64 & 1,72 \\
Total & 31 & - & - & - & - \\
\hline CV (\%) & & 7,55 & 6,58 & 3,45 & 4,55 \\
Média & & 17029 & 26219 & 23,13 & 28,84
\end{tabular}



$\mathrm{p}-\mathrm{SW}^{* *}$
0,48
0,61
$0,93 \quad 0,65$

"significativo a $5 \%$ de probabilidade de erro pelo teste $\mathrm{F}^{* *}$ probabilidade de erro do teste de Shapiro Wilk's.

Os tratamentos influenciaram significativamente a média dos caracteres produtividade de raízes (PR), produtividade de parte aérea (PPA) e teor de amido nas raízes (AM) (Tabela 2). O que aponta no sentido de que a expressão fenotípica desses caracteres na cultivar BRS 399 é influenciada pelo manejo da irrigação e da cobertura do solo. Forte influência da irrigação na expressão desses caracteres em mandioca já havia sido relatada por Ghuman e Lal (1983), Souza et al. (2010), Pastrana et al. (2015), Lima et al. (2015), Adjebeng-Danquah et al. (2016). Já a influência da irrigação e da cobertura do solo sobre a produtividade de raízes de mandioca havia sido relatada por Ghuman e Lal (1983) na ordem de 45\%.

Os fatores irrigação e cobertura do solo, não influenciaram o caráter tempo para o cozimento (TC). O fato de todos os tratamentos terem apresentado TC inferiores a 30 min (Tabela 2) pode ser explicado tanto por a colheita ter sido realizada durante o período de elevada qualidade culinária das raízes de mandioca destinadas a comercialização in natura na região do Cerrado do Brasil Central (VIEIRA et al., 2015b), como também pela estabilidade de cozimento da cultivar de mandioca de mesa BRS 399 (VIEIRA et al., 2018).

A ausência de interação significativa entre os fatores para as médias de todos os caracteres aferidos (Tabela 2) é indicativo da baixa influência do fator safra quando comparado à influência da irrigação e da cobertura plástica do solo na expressão dos caracteres avaliados. Os coeficientes de variação das análises de variância variaram de 3,55\% para o caráter porcentagem de amido nas raízes a 7,55\% para o caráter produtividade de raízes, indicando a elevada exatidão experimental do experimento (Tabela 2).

Os tratamentos testados influenciaram de maneira diferenciada a produtividade de parte aérea, sendo os mesmos particionados em quatro grupos individuais (Tabela 3 ). O tratamento que resultou na maior produtividade de parte aérea foi com irrigação e com cobertura plástica (26.774 kg ha-1), média essa $197 \%$ superior à observada no tratamento sem irrigação e sem cobertura plástica, $90 \%$ superior à observada no tratamento sem irrigação e com cobertura plástica e $47 \%$ superior à média aferida no tratamento com irrigação e sem cobertura plástica. Incrementos significativos, em razão da irrigação, na parte aérea já haviam sido reportados em mandioca por Souza et al. (2010). O aumento na produtividade de parte aérea é importante pelo fato do caráter estar relacionado ao fornecimento de manivas-sementes para novos plantios e a utilização da parte aérea como fonte de proteína na alimentação animal (FERNANDES et al., 2016).

Tabela 3. Agrupamento de médias dos caracteres produtividade de parte aérea sem a cepa em kg $\mathrm{ha}^{-1}$ (PPA), produtividade de raízes em $\mathrm{kg} \mathrm{ha}^{-1}$ (PR) e porcentagem de amido nas raízes (AM) avaliados na cultivar de mandioca BRS 399, nas safras 2015/2016 (S1) e 2016/2017 (S2) submetida aos tratamentos canteiro desnudo sem irrigação (CSPSI), canteiro desnudo e com irrigação complementar (CSPCI), canteiro coberto com plástico sem irrigação complementar (CCPSI) e canteiro coberto com plástico e com irrigação complementar (CCPCI).

\begin{tabular}{lccc}
\hline Tratamentos & PPA & PR & AM \\
& & & \\
\hline CSPSI & $9014 \mathrm{~d}$ & $18838 \mathrm{~d}$ & $23,85 \mathrm{a}$ \\
$\mathrm{CSPCl}$ & $18212 \mathrm{~b}$ & $29167 \mathrm{~b}$ & $23,50 \mathrm{a}$ \\
$\mathrm{CCPSI}$ & $14116 \mathrm{c}$ & $21245 \mathrm{c}$ & $23,03 \mathrm{a}$ \\
$\mathrm{CCPCl}$ & $26774 \mathrm{a}$ & $35625 \mathrm{a}$ & $22,14 \mathrm{~b}$ \\
\hline
\end{tabular}

médias seguidas por letras distintas na coluna não pertencem ao mesmo grupo, a 5\% de probabilidade de erro, pelo teste de agrupamento de médias de Scott e Knott.

Quanto às médias de produtividade de raízes (PR), os tratamentos testados foram divididos em quatro grupos (Tabela 3). 0 tratamento que apresentou a maior produtividade de raízes foi o com irrigação e com cobertura plástica (35.625 kg ha ${ }^{-1}$ ), média $89 \%$ superior à observada no tratamento sem irrigação e sem cobertura plástica, $67 \%$ superior à observada no tratamento sem irrigação e com cobertura plástica e $22 \%$ superior à média aferida no tratamento com irrigação e sem cobertura 
plástica.

Na literatura são reportados aumentos na PR em razão da irrigação de $45 \%$ em colheita efetuada aos 12 meses após o plantio (GHUMAN; LAL, 1983), de $54 \%$ em colheita efetuada aos 18 meses após o plantio (SOUZA et al., 2010), de $56 \%$ em colheita efetuada aos 9 meses após o plantio (PASTRANA et al., 2015) e de $27 \%$ em colheita efetuada aos 10 meses após o plantio (ADJEBENG-DANQUAH et al., 2016), revelando forte influência da irrigação sobre o caráter PR. Segundo Alves e Setter (2000), esse aumento de produtividade está relacionado à otimização da condutância estomática, que eleva a eficiência de uso da água, por meio de maiores taxas de transpiração, assimilação de carbono e água pelas raízes. No presente estudo, não houve influência da presença de plantas daninhas na manifestação da PR em razão dos tratamentos terem sido mantidos livres de plantas daninhas durante todo o ciclo da mandioca. Entretanto, em casos em que a lavoura não for mantida no limpo, nos primeiros 120 dias após o plantio, a presença de plantas daninhas poderá influenciar negativamente a expressão da PR (FIALHO et al., 2017). Passados os primeiros 120 dias, continua importante a manutenção da lavoura no limpo visando melhor aproveitamento denutrientes, água e insolação pela planta bem como a facilidade de tratos culturais e colheita (FIALHO et al., 2017).

Por sua vez, o tratamento sem irrigação e com cobertura do solo, propiciou ganho de $13 \%$ na PR em relação ao tratamento sem irrigação e sem cobertura de solo (Tabela 3), incremento de produtividade idêntico ao relatado por AdjebengDanquah et al. (2016), em colheita efetuada aos dez meses após o plantio. É importante relatar que as grandes vantagens da cobertura plástica do solo estão relacionadas ao controle de plantas daninhas e a consequente diminuição de mão-deobra para capina (ABOUZIENA; HAGGAG, 2016), aos aumentos da temperatura do solo e da disponibilidade de água e de nutrientes (ECHER et al., 2015), diminuição da erosão pela proteção do solo (LIMA et al., 2015), entre outras vantagens.

Cenário diferente foi observado para porcentagem de amido nas raízes (AM), em que a média no tratamento com irrigação e com plástico foi inferior à observada nos demais tratamentos. Entretanto, no cultivo de mandioca de mesa tal cenário não é impeditivo para a adoção da tecnologia por partes dos produtores, uma vez que tal caráter só seria importante no caso da utilização das raízes para produção de amido ou fécula e caso prejudicasse o cozimento e consequentemente a qualidade culinária das raízes.

\section{Conclusão}

O uso da irrigação e da cobertura plástica do solo, de forma isolada ou conjunta, proporcionam acréscimos consideráveis na produtividade de raízes e de parte aérea de mandioca.

\section{Agradecimentos}

Os autores agradecem à Empresa Brasileira de Pesquisa Agropecuária, à Fundação Banco do Brasil e ao Conselho Nacional de Desenvolvimento Científico pelo apoio financeiro.

\section{Referências}

ABOUZIENA, H.F.; HAGGAG, W.M. Weed control in clean agriculture: a review. Planta Daninha, v.34, n.2, p.377-392, 2016. http://dx.doi.org/10.1590/s0100$\underline{83582016340200019}$

ADJEBENG-DANQUAH, J.; GRACEN, V.E.; ASANTE, I.K.; MANU-ADUENING, J. Genetic variability in storage root bulking of cassava genotypes under irrigation and no irrigation. Agriculture \& Food Security, v.5, n.9, 2016. http://dx.doi.org/10.1186/s40066-016-0055-7

ALLEN, R. G.; PEREIRA, L. S.; RAES, D.; SMITH, M. Crop evapotranspiration: guidelines for computing crop water requirements. Roma: Food and Agriculture Organization, 1998.

ALVES, A.A.C.; SETTER, T.L. Response of cassava to water deficit: leaf area growth and abscisic acid. Crop Science, v.40, n.1, p.131-137, 2000. http://dx.doi.org/10.2135/cropsci2000.401131x

ANTONINI, J.C.A.; FIALHO, J.F.; VIEIRA, E.A. Irrigação. In: FIALHO, J.F.; VIEIRA, E.A.; BORGES, A.L. Cultivo da mandioca para região do Cerrado, Brasília: Embrapa Cerrados, 2017. p. 24-26.

BORGES, M.F.; FUKUDA, W.M G.; ROSSETTI, A.G. Avaliação de variedades de mandioca para consumo humano. Pesquisa Agropecuária Brasileira, v.37, n.11, p.1559-1565, 2002. http://dx.doi.org/10.1590/S0100- 
$204 \times 2002001100006$

CRUZ, C.D. Genes Software - extended and integrated with the R, Matlab and Selegen. Acta Scientiarum, v.38, n.4, p.547-552, 2016. http://dx.doi.org/10.4025/actasciagron.v38i4.326 $\underline{29}$

ECHER, M.M.; DALASTRA, G. M.; HACHMANN, T. L.; KLOSOWSKI, E.S.; GUIMARÃES, V.F. Agronomic performances of Park Choi grown with different soil cover. Horticultura Brasileira, v.33, n.2, p.261-266, 2015.

http://dx.doi.org/10.1590/S0102$\underline{053620150000200020}$

EL-SHARKAWY, M.A. Cassava biology and physiology. Plant Molecular Biology, v.56, n.4, p.481-501, 2004. http://dx.doi.org/10.1007/s11103-005-2270-7

EMBRAPA. Centro Nacional de Pesquisa em solos. Sistema brasileiro de classificação de solos. Brasília: Embrapa, 2018.

EMBRAPA. Serviço Nacional de Levantamento e Conservação de Solos. Manual de métodos de análise de solo. Rio de Janeiro: Embrapa, 1979.

FERNANDES, F.D.; GUIMARÃES JÚNIOR, R.; VIEIRA, E.A.; FIALHO, J.F.; MALAQUIAS, J.V. Produtividade e valor nutricional da parte aérea e de raízes tuberosas de oito genótipos de mandioca de indústria. Revista Brasileira de Saúde e de Produção Animal, v.17, n.1, p.1-12, $2016 . \quad$ http://dx.doi.org/10.1590/S1519$\underline{99402016000100001}$

FIALHO, J.F.; SOUSA, D.M.G.; VIEIRA, E.A. Manejo do solo no cultivo de mandioca. In: FIALHO, J.F.; VIEIRA, E.A. Mandioca no Cerrado: orientações técnicas, Brasília: Embrapa Cerrados, 2013. p. 3960.

FIALHO, J.F.; VIEIRA, E.A. Manejo e tratos culturais da mandioca. In: FIALHO, J.F.; VIEIRA, E.A. Mandioca no Cerrado: orientações técnicas. Brasília: Embrapa Cerrados, 2013. p. 61-88.

FIALHO, J.F.; VIEIRA, E.A.; CARVALHO, J.E.B. Tratos culturais. In: FIALHO, J.F.; VIEIRA, E.A.; BORGES, A.L. Cultivo da Mandioca para Região do Cerrado, Brasília: Embrapa Cerrados, 2017. p.
$34-36$

FUHRMANN, E.; VIEIRA, E.A.; FIALHO, J.F.; FALEIRO, F.G.; CARVALHO, L.J.C.B. Agronomic performance and biochemical attributes of yellow-pulped elite sweet cassava clones. Científica, v.47, n.1, p.77-82, 2019. http://dx.doi.org/10.15361/1984-

5529.2019v47n1p77-82

GHUMAN, B.S.; LAL, R. Mulch and irrigation effects on plant-water relations and performance of cassava and sweet potato. Field Crops Ressearch, v.7, n.1, p.13-29, 1983. http://dx.doi.org/10.1016/0378-4290(83)90003-5

GROSMANN, J.; FREITAS, A.G. Determinação do teor de matéria seca pelo método do peso específico em raízes de mandioca. Revista Agronômica, v.14, n.160-162, p.75-80, 1950.

LIMA, C.A.; MONTENEGRO, A.A.A.; SANTOS, T.E.M.; ANDRADE, E.M.; MONTEIRO, A.L.N. Práticas agrícolas no cultivo da mandioca e suas relações com o escoamento superficial, perdas de solo e água. Revista Ciência Agronômica, v.46, n.4, p.697-706, 2015. http://dx.doi.org/10.5935/1806-6690.20150056

MENDONÇA, R.M.; VIEIRA, E.A.; FIALHO, J.F.; RIBEIRO, M.R.; SENA, J.C.S.; PAIVA, W.M.; MALAQUIAS, J.V. Agronomic performance of sweet cassava cultivars. Horticultura Brasileira, v.38, n.4, p.434-438, 2020. http://dx.doi.org/10.1590/s0102-0536202004015

PASTRANA, F.E.; ALVIZ, H.S.; SALCEDO, J.G. Respuesta de dos cultivares de yuca (Manihot esculenta Crantz) (CM 3306-4 y MCOL 2215) a la aplicación de riego em condiciones hídricas diferentes. Acta Agronômica, v.64, n.1, p.48-53, 2015.

https://doi.org/10.15446/acag.v64n1.43935

PAZ, R.B.O.; COSTA, C.H.M.; VIEIRA, E.A.; COELHO, M.V.; CRUZ, S.C.S.; MACHADO, L.B. Desempenho agronômico de cultivares de mandioca de mesa em ambiente do cerrado. Colloquium Agrariae, v.16, n.3, p.37-47, 2020. http://dx.doi.org/10.5747/ca.2020.v16.n3.a370

$R$ CORE TEAM R: a language and environment for statistical computing. Viena: $R$ Foundation for 
Statistical Computing, 2017. Available at: https://www.R-project.org/. Accessed: jun 20 2019.

SCOTT, A.J.; KNOTT, M. A cluster analysis methods for grouping means in the analysis of variance. Biometrics, v.30, n.3, p.507-512, 1974. https://doi.org/10.2307/2529204

SILVA, K.N.; VIEIRA, E.A.; FIALHO, J.F.; CARVALHO, L.J.C.B.; SILVA, M.S. Potencial agronômico e teor de carotenoides em raízes de reserva de mandioca. Ciência Rural, v.44, n.8, p.1348-1354, $2014 . \quad$ http://dx.doi.org/10.1590/0103$8478 \mathrm{cr} 20130606$

SOUZA, M.J.L.; VIANA, A.E.S.; MATSUMOTO, S.N.; VASCONCELOS, R.C.; SEDIYAMA, T.; MORAIS, O.M. Características agronômicas da mandioca relacionadas à interação entre irrigação, épocas de colheita e cloreto de mepiquat. Acta Scientiarium. Agronomy, v.32, n.1, p.45-53, 2010.

http://dx.doi.org/10.4025/actasciagron.v32i1.720

VIEIRA, E.A.; FIALHO, J.F.; CARVALHO, L.J.C.B. Performance of cassava genotypes for industrial use in areas of the Urucuia River Valley region. Revista de Ciências Agrárias - Amazonian Journal of Agricultural and Environmental Sciences, v.58, n.3, p.314-318, 2015a. http://dx.doi.org/10.4322/rca.1843

VIEIRA, E.A.; FIALHO, J.F.; CARVALHO, L.J.C.B.; MALAQUIAS, J.V.; FERNANDES, F.D. Desempenho agronômico de acessos de mandioca de mesa em área de Cerrado no município de Unaí, região noroeste de Minas Gerais. Científica, v.43, n.4, p.371-377, 2015b. https://doi.org/10.15361/1984-

$\underline{5529.2015 v 43 n 4 p 371-377}$

VIEIRA, E.A.; FIALHO, J.F.; JÚLIO, L.; CARVALHO, L.J.C.B.; DALLA CORTE, J.L.; RINALDI, M.M.; OLIVEIRA, C.M.; FERNADES, F.D.; ANJOS, J.R.N. Sweet cassava cultivars with yellow or cream root pulp developed by participatory breeding. Crop Breeding and Applied Biotechnology, v.18, n.4, p.450-454, 2018. https://doi.org/10.1590/1984$\underline{70332018 \mathrm{v} 18 \mathrm{n} 4 \mathrm{c} 67}$

VIEIRA, E.A.; FIALHO, J.F.; SILVA, M.S.; PAULAMORAES, S.V.; OLIVEIRA, C.M.; ANJOS, J.R.N.;
RINALDI, M.M.; FERNADES, F.D.; GUIMARÃES JÚNIOR, R. BRS Japonesa: new sweet cassava cultivar for the Distrito Federal region. Crop Breeding and Applied Biotechnology, v.11, n.2, p.93-196, 2011. https://doi.org/10.1590/S1984$\underline{70332011000200014}$ 